\title{
Common variants of the UMOD promoter associated with blood pressure in a community-based Chinese cohort
}

\author{
Jia Han ${ }^{1,2,3,4}$, Yuqing Chen ${ }^{1,2,3,4}$, Ying Liu ${ }^{1,2,3,4}$, Yu Liang ${ }^{1,2,3,4}$, Xingyu Wang ${ }^{5}$, Lisheng Liu ${ }^{5}$, Fang Wang ${ }^{1,2,3,4}$, \\ Luxia Zhang ${ }^{1,2,3,4}$, Hong Zhang ${ }^{1,2,3,4}$ and Haiyan Wang ${ }^{1,2,3,4}$
}

Hypertension is an important risk factor for chronic kidney disease. The kidney, in turn, has an important role in the regulation of blood pressure (BP). On the basis of a genome-wide association study, single-nucleotide polymorphisms in the uromodulin (UMOD) promoter region had been considered to influence both renal sodium reabsorption and BP. In this study, we asked whether common variants across the UMOD gene influence BP in a community-based Chinese cohort. We screened seven common variants across the UMOD locus in a community-based population from Beijing, including 1000 individuals with $48 \%$ males and an average age of $63.7 \pm 9.0$ years. The urinary UMOD concentration was measured by enzyme-linked immunosorbent assay. We then analyzed the association of common variants of UMOD with BP. The UMOD promoter common variant rs13333226 G/A is associated with diastolic BP (DBP), and G allele carriers have higher DBP compared with A/A homozygotes $(P=0.035)$. The variant rs6497476 C/T predicted the DBP level, with $C$ homozygotes having a higher DBP compared with CT heterozygotes and T homozygotes $(P=0.025)$. Urinary UMOD excretion was correlated with urinary sodium excretion $\left(R=0.239, P=0.656^{*} 10^{-13}\right)$. We determined that common variants of $U M O D$ are associated with DBP level in a community-based Chinese cohort.

Hypertension Research (2012) 35, 769-774; doi:10.1038/hr.2012.51; published online 17 May 2012

Keywords: diastolic blood pressure; single-nucleotide polymorphism; Tamm-Horsfall protein; uromodulin

\section{INTRODUCTION}

Hypertension (HTN) is an important risk factor for chronic kidney disease, and the kidney, in turn, has important roles in the regulation of blood pressure (BP). ${ }^{1,2}$ Enzymes, channels and receptors implicating sodium regulation within the kidney have been proven to be involved in the pathogenesis of HTN. ${ }^{3-6}$

Uromodulin $(U M O D)$ is the most abundant protein in human urine. Recently, it is found that UMOD has an effect on renal outer medullary potassium channels and thus regulate salt reabsorption along the thick ascending limb. ${ }^{7}$ Furthermore, in a genome-wide association study, one of the common variants of $U M O D$, rs13333226, is identified as being associated with HTN and cardiovascular risk in European cohorts. 8

We therefore systematically genotyped common variants across the $U M O D$ gene in a community-based cohort and explored whether common variants of the UMOD gene are associated with BP.

\section{METHODS}

Subjects

Individuals from a community-based cohort in an urban area of Beijing were included in this study. Briefly, 2310 individuals were evaluated in 2004, ${ }^{9}$ and 1504 of these individuals were re-evaluated in $2008 .^{10}$ We were able to obtain consent and prepare genomic DNA from blood leukocytes obtained from 1000 of the participants in 2008, and this population was comparable to the original cohort with respect to the general baseline data, including age $(P=0.603)$, gender $(P=0.718)$, body mass index $(P=0.466)$, systolic BP (SBP; $P=0.35)$, diastolic BP (DBP; $P=0.237)$, estimated glomerular filtration rate $(P=0.308)$, high-density lipoprotein-cholesterol $(P=0.9)$, triglycerides $(P=0.56)$ and diagnosis of HTN $(P=0.836)$. We obtained urine samples from 898 participants, and they were comparable to the 1000 subjects and to the 102 cases that gave blood, but not urine (Table 1).

BPs were measured according to the guidelines presented in the Seventh Report of the Joint National Committee on Prevention, Detection, Evaluation and Treatment of High Blood Pressure. ${ }^{11}$ Three readings were taken at 5-min intervals. The mean values of the three readings were calculated, unless the difference between the readings was $>10 \mathrm{mmHg}$, in which case, the

\footnotetext{
${ }^{1}$ Department of Medicine, Renal Division, Peking University First Hospital, Beijing, China; ${ }^{2}$ Institute of Nephrology, Peking University, Beijing, China; ${ }^{3}$ Key Laboratory of Renal Disease, Ministry of Health of China, Beijing, China; ${ }^{4}$ Key Laboratory of Chronic Kidney Disease Prevention and Treatment, Peking University, Ministry of Education, Beijing, China and ${ }^{5}$ Beijing Hypertension League Institute, Beijing, China

Correspondence: Dr Y Chen, Department of Medicine, Renal Division, Peking University First Hospital; or Institute of Nephrology, Peking University; or Key Laboratory of Renal Disease, Ministry of Health of China; or Key Laboratory of Chronic Kidney Disease Prevention and Treatment, Peking University, Ministry of Education, No. 8 Xishiku Street, Beijing 100034, China.

E-mail: cyq@bjmu.edu.cn
}

Received 4 November 2011; revised 12 January 2012; accepted 17 January 2012; published online 17 May 2012 
Table 1 Basic clinical features of the participants

\begin{tabular}{|c|c|c|c|c|c|}
\hline Items & $\mathrm{N} 1=1000$ & $\mathrm{~N} 2=898$ & $\mathrm{~N} 3=102$ & P-value (N1 and N2) & P-value (N2 and N3) \\
\hline Male (\%) & 48 & 48 & 48 & 0.998 & 0.998 \\
\hline Age (years) & $63.7 \pm 9.0$ & $63.5 \pm 9.3$ & $64.7 \pm 9.7$ & 0.773 & 0.286 \\
\hline BMI $\left(\mathrm{kg} \mathrm{m}^{-2}\right)$ & $25.3 \pm 3.8$ & $25.3 \pm 3.8$ & $25.4 \pm 3.8$ & 0.965 & 0.57 \\
\hline $\mathrm{SBP}(\mathrm{mmHg})$ & $137.8 \pm 19.9$ & $138.1 \pm 17.9$ & $140.1 \pm 17.8$ & 0.671 & 0.304 \\
\hline $\mathrm{DBP}(\mathrm{mmHg})$ & $81.0 \pm 10.2$ & $81.4 \pm 10.3$ & $81.2 \pm 10.0$ & 0.493 & 0.908 \\
\hline eGFR $\left(\mathrm{ml} \mathrm{min}{ }^{-1}\right.$ per $\left.1.73 \mathrm{~m}^{2}\right)$ & $70.8 \pm 14.9$ & $70.9 \pm 15.2$ & $70.8 \pm 14.9$ & 0.899 & 0.899 \\
\hline HDL cholesterol $\left(\mathrm{mmoll}^{-1}\right)$ & $1.3(1.1-1.6)$ & $1.4(1.2-1.7)$ & $1.3(1.1-1.6)$ & 0.028 & 0.476 \\
\hline Triglycerides $\left(\mathrm{mmol}^{-1}\right)$ & $1.3(1.0-1.8)$ & $1.3(1.0-1.8)$ & $1.2(0.9-2.0)$ & 0.918 & 0.351 \\
\hline Hypertension (\%) & 46.3 & 46.4 & 46.0 & 0.998 & 0.998 \\
\hline Anti-hypertension medication(\%) & 81.6 & 81.5 & 82.0 & 0.961 & 0.961 \\
\hline
\end{tabular}

Abbreviations: BMI, body mass index; CKD-EPI, Chronic Kidney Disease Epidemiology Collaboration; DBP, diastolic blood pressure; eGFR, estimated glomerular filtration rate; HDL, high-density lipoprotein; IQR, inter-quartile range; SBP, systolic blood pressure.

eGFR was estimated with the equation developed from the CKD-EPI ${ }^{12}$. Data presented as mean \pm s.d. for normally distributed traits, or median IQR for not normally distributed variables.

Anti-hypertension medication (\%) calculated by numbers of taking anti-hypertension medication over numbers of hypertension.

mean of the two closest measurements was used. HTN was defined as SBP $\geq 140 \mathrm{mmHg}$, DBP $\geq 90 \mathrm{mmHg}$, or the use of anti-hypertensive medications. The estimated glomerular filtration rate was estimated with the equation developed from the Chronic Kidney Disease Epidemiology Collaboration. ${ }^{12}$ In individuals undergoing antihypertensive therapies, the $\mathrm{BP}$ was imputed by adding 15 and $10 \mathrm{~mm} \mathrm{Hg}$ to the SBP and DBP, respectively, ${ }^{13}$ during analyses.

\section{Genomics}

Single-nucleotide polymorphisms (SNPs) were obtained from public SNP databases (http://www.ncbi.nlm.nih.gov/projects/SNP/; Figure 1). The genomic DNA was typed using a matrix-assisted laser desorption/ionization time-offlight mass-spectrometry system developed by Sequenom according to a published protocol, ${ }^{14}$ or by a Taqman assay with supplied probes and primers on an ABI PRISM Sequence Detection System 7500 (Applied Biosystems, Foster City, CA, USA). The reproducibility of the genotyping was verified with 50 blinded replicate samples. The SNPs evaluated in this study had minor allele frequencies of $\geqslant 4 \%$, and all were in Hardy-Weinberg equilibrium $(P>0.05)$. Although we genotyped 1000 cases, only 910 individuals were successfully genotyped for SNP rs13333226, and 879 cases for rs6497476. To prove that the missing data were randomly deleted, we compared clinical features between subgroups N1 (the whole population group), N2 (the successfully genotyped group) and N3 (the genotype failed group). No differences were identified (Supplementary Tables 1 and 2).

\section{Biochemical assays}

Urinary UMOD, sodium and creatinine were measured from stored diet spot urine specimens among a subset of 898 participants, balanced by genotype. The urinary creatinine and sodium were measured by the same means as the serum creatinine and sodium. Because of genotyping failure, only 853 cases yielded both genotyping data and urinary information for rs13333226, and 824 cases for rs6497476. These data were randomly missing without any inclusion or exclusion criteria. To prove the randomization, we compared clinical features between subgroups N1 (the whole population group), N2 (the successfully genotyped group) and N3 (the genotype failed group). No differences were identified (Supplementary Tables 3 and 4).

\section{UMOD measurement}

The measurement of urinary UMOD was adjusted according to Lau's protocol. ${ }^{15}$ First, 96-well microtiter plates were coated with polyclonal mouse anti-human UMOD antibodies (Biomedical Technologies Inc., Stoughton, MA, USA; BT-590). Urinary samples and UMOD standards (Biomedical Technologies) were then diluted and added to wells in duplicate. After $2 \mathrm{~h}$ of incubation at $37^{\circ} \mathrm{C}$, the wells were washed and monoclonal rabbit anti-human UMOD antibody (Biomedical Technologies) was added. After $1 \mathrm{~h}$ of incubation at $37^{\circ} \mathrm{C}$, goat anti-rabbit immunoglobulin
Haplotype blocks at the UMOD locus in the Chinese population
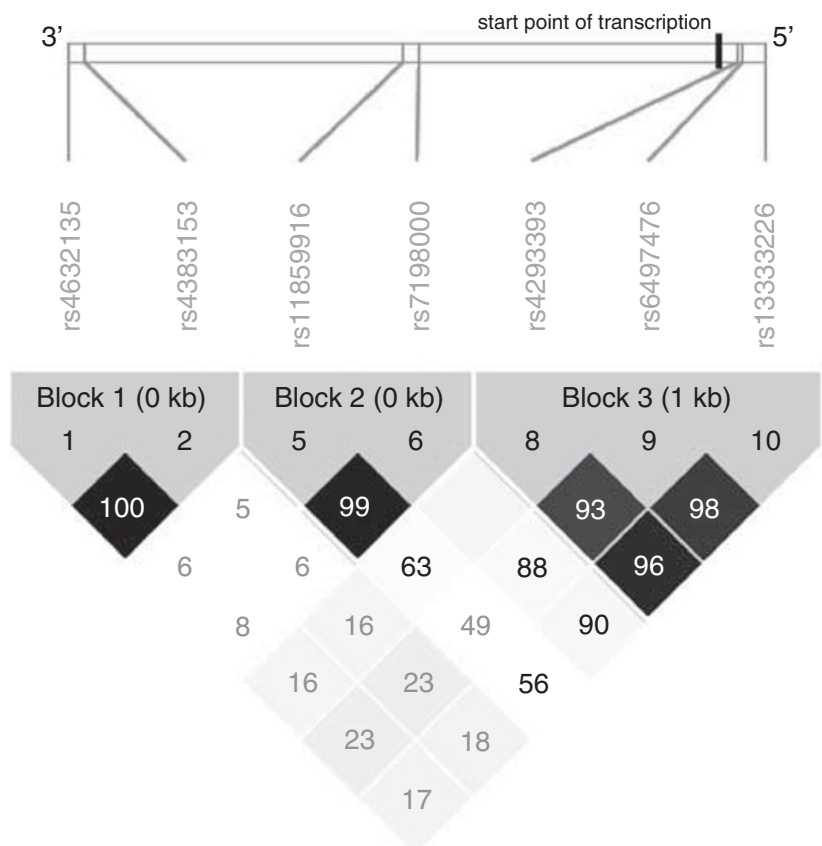

Figure 1 Haplotype blocks at the UMOD locus in the Chinese population. We used seven common variants (minor allele frequency $>5 \%$ ) to construct haplotype blocks in Haploview ${ }^{16}$ for all subjects. A full color version of this figure is available at the Hypertension Research journal online.

horseradish peroxidase (CEDARLANE CL1032AP, Canada) was added. Color was developed by the addition of TMB $\left(3,3^{\prime}, 5,5^{\prime}\right.$-tetramethylbenzidine) substrate. The reaction was stopped by adding $2 \mathrm{~N}_{2} \mathrm{SO}_{4}$, followed by reading immediately at optical density 490 and 570 . The urinary UMOD concentration was determined by referring to a standard curve.

\section{Statistical analyses}

The pairwise linkage disequilibrium between each common SNP pair across the $U M O D$ locus was quantified as $\mathrm{D}^{\prime}$ or $r^{2}$ with Haploview software. ${ }^{16}$ Haplotype homozygosities were confirmed with plink software (URL: http:// pngu.mgh.harvard.edu/purcell/plink/). ${ }^{17}$

The baseline characteristics were computed as the mean \pm s.d. (or mean \pm s.e.m.) for normally distributed traits and median (inter-quartile range) for 
non-normally distributed variables. The analyses were conducted with SPSS (Statistical Package for the Social Sciences) software (SPSS v13.0; Chicago, IL, USA). If traits were not normally distributed, then their values were tested by non-parametric methods (Kruskal-Wallis or median tests). Univariate analyses were performed to evaluate the effects of particular SNPs on continuous traits (such as BP) and dichotomous traits (such as HTN status), and were adjusted by age and sex (as covariates).

To quantify the effect of a particular genetic variant on a BP trait and to normalize such values across traits, we estimated the coefficient of determination (adjusted $R^{2}$ ) in general linear models (analysis of variance or regression) in the presence or absence of the genotype. Thus, the difference in the adjusted $R^{2}$ (full model minus model without genotype) represents the contribution of the genotype to the trait, and multiplication by 100 yields the coefficient of determination as a percentage of the trait variance, where variance $=$ s.d. ${ }^{2}$

\section{RESULTS}

Linkage disequilibrium at the UMOD genetic locus in the cohort The observed genotype frequencies of the seven polymorphisms were all in the Hardy-Weinberg equilibrium. We used seven common variants (minor allele frequency $>5 \%$ ) to construct haplotype blocks in Haploview ${ }^{16}$ for all subjects. The linkage disequilibrium analysis revealed three blocks across the UMOD genes, such that the SNPs in the $U M O D$ promoter region, intron and $3^{\prime}$ downstream region were all highly correlated within each block, and the $r^{2}$ reached at least 0.93 (Figure 1).

Association of common variants of the UMOD promoter with DBP Because the SNPs were highly correlated within each block, we tested the associations of seven common variants with DBP and SBP directly. None of the seven SNPs was associated with SBP. The common variant rs13333226 G/A predicted the DBP level, with G allele carriers having a higher DBP than A homozygotes $(P=0.035)$ (Figure 2a; Table 2). Another SNP, rs6497476 C/T, also predicted the DBP level, with $\mathrm{C}$ carriers having a higher DBP than $\mathrm{T}$ homozygotes $(P=0.025)$ (Figure $2 \mathrm{~b})$. We also detected the effects of gender, age, body mass index and gene (rs13333226 and rs6497476) on DBP levels by linear regression; a model combining age, gender, body mass index and gene predicted the BP level $(P<0.001)$, whereas rs13333226 and rs6497476 themselves accounted for approximately $0.4 \%-0.5 \%$ of the DBP variance (Figure $2 \mathrm{a}$ and $\mathrm{b}$ ). Other common variants were not identified as being associated with DBP.

\section{Correlation between urinary $U M O D$ excretion and urinary sodium} excretion in the cohort

Urinary UMOD and sodium excretion were calculated as the urinary UMOD (sodium)/creatinine ratio. We found that the urinary $\mathrm{UMOD} /$ creatinine ratio correlated with the urinary sodium/ creatinine ratio (Spearman's $R=0.239, P=0.656^{\star} 10^{-13}$, Supplementary Figure 1)

Therefore, we explored whether UMOD haplotypes or variants that were associated with DBP also influenced urinary sodium excretion in the cohort. As indicated in Table 3, rs13333226 A homozygotes had a higher urinary sodium/creatinine ratio than $\mathrm{G}$ allele carriers, although the $P$-value was at the marginal level. We obtained similar results for rs6497476.

We also tested the association of UMOD haplotypes or variants with the urinary $\mathrm{UMOD} /$ creatinine ratio. However, none of the variants were identified as influencing the urinary UMOD excretion.

\section{DISCUSSION}

In this study, we showed that common variants in the UMOD promoter region are associated with the continuous trait of
DBP in a community-based Chinese population. Among the three common promoter variants, rs13333226 and rs6497476 are also associated with DBP. The G allele (minor) of rs13333226 and the $\mathrm{C}$ allele (minor) of rs6497476 are associated with higher DBP.

Recent advances in molecular biology have unveiled the mechanism of HTN in certain situations to be associated with the upregulation of sodium reabsorption in the distal nephron, with an accompanying expansion of the extracellular volume. ${ }^{18,19}$ Aviv et al. ${ }^{20,21}$ reviewed previously reported clinical studies that indicated that the thick ascending limb (TAL) had a pivotal role in the susceptibility of Blacks to HTN. A mechanism was proposed in which an increase in NKCC2 activity could lead to the expansion of the extracellular volume and thus be associated with HTN. ${ }^{22}$

UMOD is synthesized by the tubular cells of the TAL and the early distal convoluted tubule of the kidney. ${ }^{23}$ It has been considered that UMOD might influence the colloidal osmotic pressure through the TAL, and thus regulate their active transport along this segment. ${ }^{24}$ Recently, it was found that UMOD had an effect on the renal outer medullary potassium channels (ROMK2), and thus increased salt reabsorption along the TAL. ${ }^{7}$ According to these findings, it appeared that UMOD excretion may induce changes in sodium reabsorption in the TAL, thus influencing sodium reabsorption in the proximal tubules as well. Because UMOD may be involved in the regulation of sodium reabsorption, it is reasonable to hypothesize that UMOD influences BP. The associations of the UMOD gene with HTN were also reported in different populations. One study from the European cohorts found that the minor G allele of rs13333226 was associated with a lower risk of HTN. ${ }^{8,25}$ However, in these cohorts, the minor $G$ allele of rs13333226 is associated with lower urinary UMOD excretion and lower urinary sodium excretion. The association of lower BP and increased sodium reabsorption appeared counterintuitive. ${ }^{8}$ In our result, the minor $G$ allele of rs13333226 was associated with higher DBP in a communitybased Chinese population; this result is opposite to those found with other cohorts. We therefore tested whether the UMOD gene correlated with renal sodium excretion. Although the $P$-values were at the marginal level, the haplotype GCC, the G minor allele of rs13333226 and the T homozygotes of rs6497476 exhibited lower urinary sodium excretion, which maintained the expected correlation between lower sodium excretion and high BP to a certain extent. The effect of rs13333226 on BP appeared to contradict that found in the previous study. However, there are several possible explanations for this discrepancy. Our results showed that the UMOD genotype was associated with diastolic pressure, not with the risk for HTN. We did not control the sodium intake in this population. Because it appeared that UMOD was involved in the regulation of sodium reabsorption, UMOD might have more complicated effects on sodium regulation and BP. Finally, the different studies involved different populations in different places, so unknown factors may interact with the gene effects.

The three SNPs (rs13333226, rs6497476 and rs4293393) that we genotyped here are common SNPs, changed from purine to pyrimidine, and were reported to be associated with serum creatinine, BP or plasma uric acid. ${ }^{8,26}$ The population genetic studies suggested that these SNPs may influence the transcriptional level and thus regulate UMOD expression and finally change UMOD excretion. However, further cell research must be conducted to confirm that they are functional SNPs.

Our study also has several limitations. Because our study was observational, the possibility of residual confounding by an 
Uromodulin promoter common variants: effects on diastolic blood pressure in the cohort

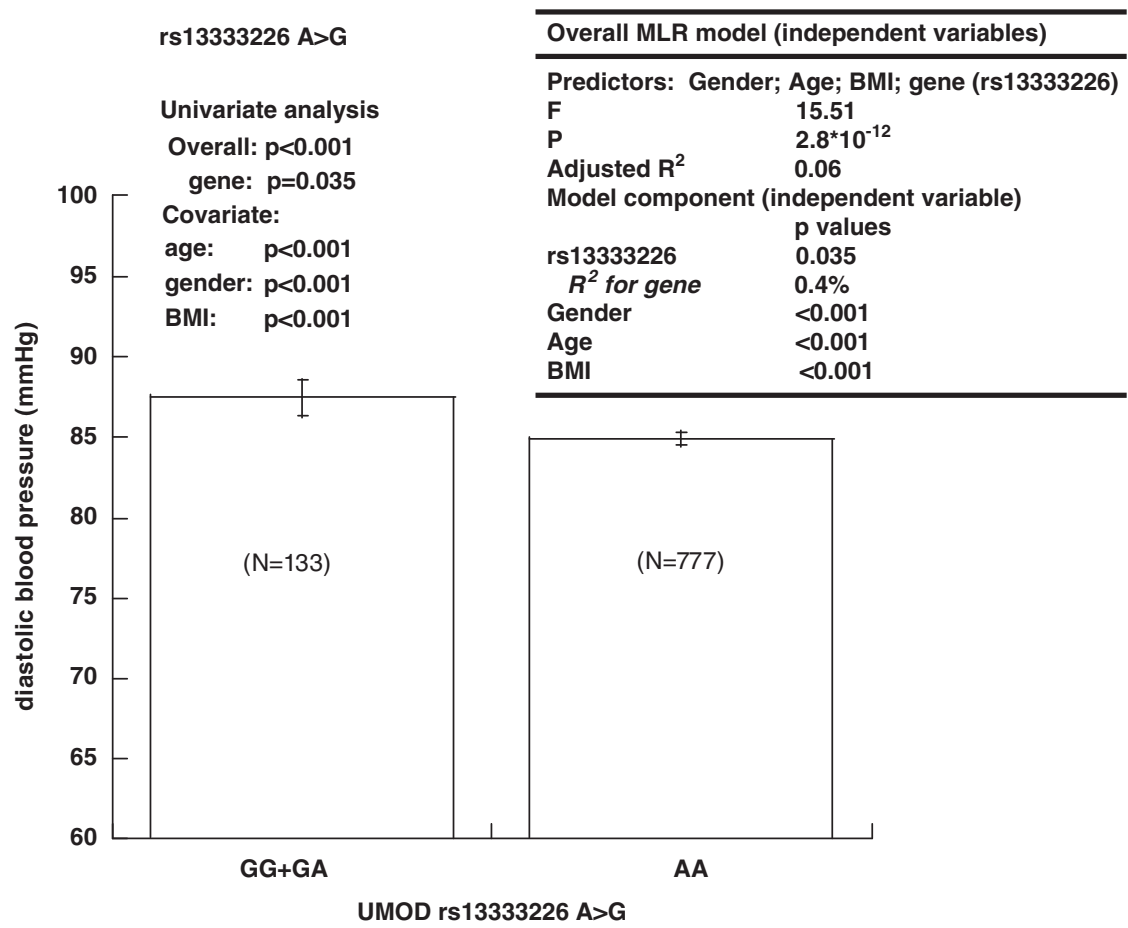

b Uromodulin promoter common variants: effects on diastolic blood pressure in the cohort

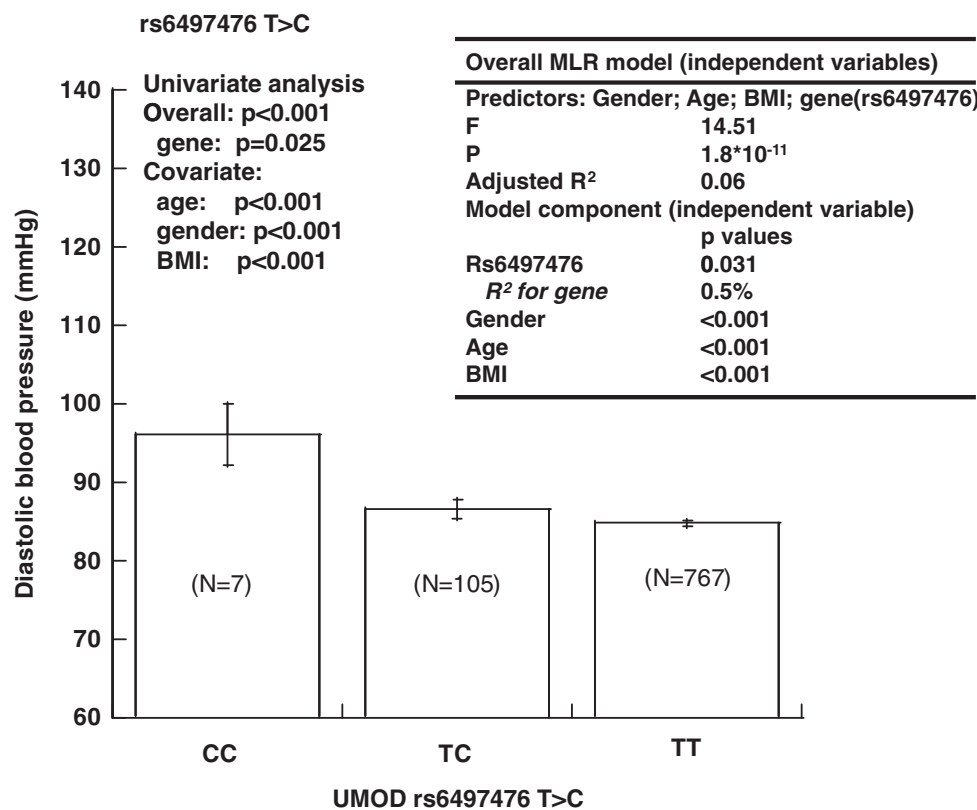

Figure 2 UMOD promoter common variants: effects on diastolic blood pressure in community based cohort of Chinese population. Diastolic blood pressure and result of multiple liner regression were shown. The rs $13333226 \mathrm{G}$ allele carriers have higher diastolic blood pressure compared with A homozygotes. Another SNP rs6497476 C allele carriers have higher diastolic blood pressure compared with $\mathrm{T}$ homozygotes. Data was presented as mean \pm s.e.m. (a) rs13333226 and DBP: DBP was showed according to different genotypes: GG + GA $87.5 \pm 1.1 \mathrm{mmHg}$; GA $84.9 \pm 0.4 \mathrm{mmHg}$. (b): rs6497476 and DBP: DBP was showed according to different genotypes: CC $96.0 \pm 3.9 \mathrm{mmHg}$; TC $86.5 \pm 1.2 \mathrm{mmHg}$; TT $84.8 \pm 0.4 \mathrm{mmHg}$.

unmeasured covariate exists. Additionally, the genotyping failure rate for rs6497476 is relatively high $(121 / 1000=12 \%)$. Although we performed genotyping for rs6497476 by matrix-assisted laser desorption mass spectrometry, which is a good and reliable tool for SNP genotyping, the method still had certain limitations. In our study, the DNA quality was sufficient, as the failure rates of other 
Table 2 Subject characteristics by genotypes of rs 13333226

\begin{tabular}{|c|c|c|c|}
\hline \multirow[b]{2}{*}{ Items } & \multicolumn{2}{|c|}{ Genotyping } & \multirow[b]{2}{*}{ P-value } \\
\hline & $A A$ & $G G+G A$ & \\
\hline N & 777 & 133 & \\
\hline Male (\%) & 49 & 46 & 0.599 \\
\hline Age (years) & $63.9 \pm 9.3$ & $62.4 \pm 9.5$ & 0.095 \\
\hline BMI $\left(\mathrm{kg} \mathrm{m}^{-2}\right)$ & $25.3 \pm 3.9$ & $25.4 \pm 3.1$ & 0.608 \\
\hline $\mathrm{SBP}(\mathrm{mmHg})$ & $138.1 \pm 17.6$ & $139.6 \pm 18.1$ & 0.356 \\
\hline DBP $(\mathrm{mmHg})$ & $81.2 \pm 10.2$ & $83.1 \pm 10.7$ & 0.046 \\
\hline eGFR (ml min ${ }^{-1}$ per $\left.1.73 \mathrm{~m}^{2}\right)$ & $70.6 \pm 14.9$ & $70.5 \pm 15.6$ & 0.91 \\
\hline Triglycerides $\left(\mathrm{mmoll}^{-1}\right)$ & $1.3(0.9-1.7)$ & $1.3(1.0-1.9)$ & 0.07 \\
\hline HDL cholesterol $\left(\mathrm{mmol}^{-1}\right)$ & $1.3(1.1-1.6)$ & $1.3(1.1-1.5)$ & 0.124 \\
\hline
\end{tabular}

Abbreviations: BMI, body mass index; CKD-EPI, Chronic Kidney Disease Epidemiology Collaboration; DBP, diastolic blood pressure; eGFR, estimated glomerular filtration rate; HDL, high-density lipoprotein; IQR, inter-quartile range; SBP, systolic blood pressure.

eGFR was estimated with the equation developed from the CKD-EPI ${ }^{12}$. Data presented as mean \pm s.d. for normally distributed traits, or median IQR for not normally distributed variables.

Table 3 UMOD common variants and urinary sodium/creatinine ratio

\begin{tabular}{ccccc}
\hline \multicolumn{4}{c}{ Urinary sodium/creatinine $\left(\mu \mathrm{mol} \mathrm{mmol}^{-1}\right)$} & P-value \\
\hline rs13333226 & $\mathrm{AA}(N=734)$ & $\mathrm{GG}+\mathrm{GA}(N=119)$ & \\
& 22.97 & 21.37 & 0.068 \\
$\mathrm{rs6497476}$ & $\mathrm{CC}(N=6)$ & $\mathrm{CT}(N=96)$ & $\mathrm{TT}(\mathrm{N}=722)$ & \\
& 23.38 & 20.81 & 22.88 & 0.047 \\
\hline
\end{tabular}

Abbreviation: UMOD, uromodulin.

\section{Uromodulin (UMOD, Tamm-Horsfall protein): \\ Working hypothesis for pathophysiological} consequences of common variants in the promoter

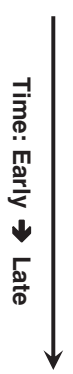

Concept:

$$
\begin{gathered}
\text { Gene } \\
\downarrow \\
\text { Cellular process }
\end{gathered}
$$

Biochemical trait(s)

$$
\downarrow
$$

Physiological trait(s)

$$
\downarrow
$$

Disease trait
Application to UMOD:

UMOD promoter common variants $\triangle$ UMOD TALH/DCT expression/secretion Influence of sodium reabsorption $\downarrow$

Regulation of blood pressure $\downarrow$
Figure 3 Uromodulin (UMOD): working hypothesis for pathophysiological consequences of common variants in the promoter.

SNPs were low. Therefore, the primers for these SNPs might be the major limitation resulting in genotyping failure.

In summary, we identified the association of common variants of $U M O D$ with DBP in a Chinese cohort, suggesting that UMOD has important roles in the mechanisms of HTN. We described our hypothesis in Figure 3. The common variants of the UMOD promoter will influence the mRNA level and thus regulate the expression/ secretion of UMOD in the renal TALs. The renal TALs have important roles in sodium reabsorption, ${ }^{20,21}$ and UMOD may regulate sodium reabsorption in this tissue ${ }^{24}$ and thus regulate BP. One of our results appeared to be contradicted by previous studies, indicating that the real mechanism of UMOD in the regulation of BP needs to be further explored.

\section{ACKNOWLEDGEMENTS}

The study was financially supported by the National Natural Science Foundation of China (81070587) and a grant of the Chinese 985 Project (BMU20110156).

1 Rettig R, Folberth C, Kopf D, Stauss H, Unger T. Role of the kidney in the pathogenesis of primary hypertension. Clin Exp Hypertens A 1990; 12: 957-1002.

2 Hall JE. The kidney, hypertension, and obesity. Hypertension 2003; 41: 625-633.

3 Guyton AC, Coleman TG, Cowley AJ, Scheel KW, Manning RJ, Norman RJ. Arterial pressure regulation. Overriding dominance of the kidneys in long-term regulation and in hypertension. Am J Med 1972; 52: 584-594.

4 Guyton AC. Long-term arterial pressure control: an analysis from animal experiments and computer and graphic models. Am J Physiol 1990; 259: R865-R877.

5 Izzo JJ. The sympathoadrenal system in the maintenance of elevated arterial pressure. J Cardiovasc Pharmacol 1984; 6: S514-S521.

6 Hall JE. Historical perspective of the renin-angiotensin system. Mol Biotechnol 2003; 24: 27-39.

7 Renigunta A, Renigunta V, Saritas T, Decher N, Mutig K, Waldegger S. Tamm-Horsfall glycoprotein interacts with renal outer medullary potassium channel ROMK2 and regulates its function. J Biol Chem 2011; 286: 2224-2235.

8 Padmanabhan S, Melander O, Johnson T, Di Blasio AM, Lee WK, Gentilini D, Hastie CE, Menni C, Monti MC, Delles C, Laing S, Corso B, Navis G, Kwakernaak AJ, van der Harst P, Bochud M, Maillard M, Burnier M, Hedner T, Kjeldsen S, Wahlstrand B, Sjogren M, Fava C, Montagnana M, Danese E, Torffvit O, Hedblad B, Snieder H, Connell JM, Brown M, Samani NJ, Farrall M, Cesana G, Mancia G, Signorini S, Grassi G, Eyheramendy S, Wichmann HE, Laan M, Strachan DP, Sever P, Shields DC, Stanton A, Vollenweider P, Teumer A, Volzke H, Rettig R, Newton-Cheh C, Arora P, Zhang F, Soranzo N, Spector TD, Lucas G, Kathiresan S, Siscovick DS, Luan J, Loos RJ, Wareham NJ, Penninx BW, Nolte IM, McBride M, Miller WH, Nicklin SA, Baker AH, Graham D, McDonald RA, Pell JP, Sattar N, Welsh P, Munroe P, Caulfield MJ, Zanchetti A, Dominiczak AF. Genome-wide association study of blood pressure extremes identifies variant near UMOD associated with hypertension. PLoS Genet 2010; 6: e1001177.

9 Zhang L, Zuo L, Xu G, Wang F, Wang M, Wang S, Lv J, Liu L, Wang H. Communitybased screening for chronic kidney disease among populations older than 40 years in Beijing. Nephrol Dial Transplant 2007; 22: 1093-1099.

10 Wang F, Zhang L, Zuo L, Liu L, Wang H. Mortality and renal function decline among a community-based Chinese population with normal or mildly impaired renal function. Nephrol Dial Transplant 2011; 26: 2847-2852.

11 Chobanian AV, Bakris GL, Black HR, Cushman WC, Green LA, Izzo JJ, Jones DW, Materson BJ, Oparil S, Wright JJ, Roccella EJ. The Seventh Report of the Joint National Committee on Prevention, Detection, Evaluation, and Treatment of High Blood Pressure: the JNC 7 report. JAMA 2003; 289: 2560-2572.

12 Levey AS, Stevens LA, Schmid CH, Zhang YL, Castro AR, Feldman HI, Kusek JW, Eggers $\mathrm{P}$, Van Lente $\mathrm{F}$, Greene $\mathrm{T}$, Coresh J. A new equation to estimate glomerular filtration rate. Ann Intern Med 2009; 150: 604-612.

13 Tobin MD, Sheehan NA, Scurrah KJ, Burton PR. Adjusting for treatment effects in studies of quantitative traits: antihypertensive therapy and systolic blood pressure. Stat Med 2005; 24: 2911-2935.

14 Buetow KH, Edmonson M, MacDonald R, Clifford R, Yip P, Kelley J, Little DP, Strausberg R, Koester H, Cantor CR, Braun A. High-throughput development and characterization of a genomewide collection of gene-based single nucleotide polymorphism markers by chip-based matrix-assisted laser desorption/ionization time-offlight mass spectrometry. Proc Natl Acad Sci USA 2001; 98: 581-584.

15 Lau WH, Leong WS, Ismail Z, Gam LH. Qualification and application of an ELISA for the determination of Tamm Horsfall protein (THP) in human urine and its use for screening of kidney stone disease. Int J Biol Sci 2008; 4: 215-222.

16 Barrett JC, Fry B, Maller J, Daly MJ. Haploview: analysis and visualization of LD and haplotype maps. Bioinformatics 2005; 21: 263-265.

17 Purcell S, Neale B, Todd-Brown K, Thomas L, Ferreira MA, Bender D, Maller J, Sklar P, de Bakker PI, Daly MJ, Sham PC. PLINK: a tool set for whole-genome association and population-based linkage analyses. Am J Hum Genet 2007; 81: 559-575.

18 Bachmann S, Metzger R, Bunnemann B. Tamm-Horsfall protein-mRNA synthesis is localized to the thick ascending limb of Henle's loop in rat kidney. Histochemistry 1990; 94: 517-523.

19 Malagolini N, Cavallone D, Serafini-Cessi F. Intracellular transport, cell-surface exposure and release of recombinant Tamm-Horsfall glycoprotein. Kidney Int 1997; 52: $1340-1350$

20 Aviv A, Hollenberg NK, Weder A. Urinary potassium excretion and sodium sensitivity in blacks. Hypertension 2004; 43: 707-713.

21 Aviv A, Hollenberg NK, Weder AB. Sodium glomerulopathy: tubuloglomerular feedback and renal injury in African Americans. Kidney Int 2004; 65: 361-368.

22 Kemter E, Rathkolb B, Bankir L, Schrewe A, Hans W, Landbrecht C, Klaften M, Ivandic B, Fuchs H, Gailus-Durner V, Hrabe DAM, Wolf E, Wanke R, Aigner B. Mutation of the $\mathrm{Na}(+)-\mathrm{K}(+)-2 \mathrm{Cl}(-)$ cotransporter NKCC2 in mice is associated with severe 
polyuria and a urea-selective concentrating defect without hyperreninemia. Am J Physiol Renal Physiol 2010; 298: F1405-F1415.

23 Rindler MJ, Naik SS, Li N, Hoops TC, Peraldi MN. Uromodulin (Tamm-Horsfall glycoprotein/uromucoid) is a phosphatidylinositol-linked membrane protein. J Biol Chem 1990; 265: 20784-20789.

24 Hoyer JR, Seiler MW. Pathophysiology of Tamm-Horsfall protein. Kidney Int 1979; 16: 279-289.
25 Ahluwalia TS, Lindholm E, Groop L, Melander O. Uromodulin gene variant is associated with type 2 diabetic nephropathy. J Hypertens 2011; 29: 1731-1734.

26 Gudbjartsson DF, Holm H, Indridason OS, Thorleifsson G, Edvardsson V, Sulem P, de Vegt F, D'Ancona FC, den Heijer M, Wetzels JF, Franzson L, Rafnar T, Kristjansson K, Bjornsdottir US, Eyjolfsson GI, Kiemeney LA, Kong A, Palsson R, Thorsteinsdottir U, Stefansson K. Association of variants at UMOD with chronic kidney disease and kidney stones-role of age and comorbid diseases. PLoS Genet 2010; 6: e1001039.

Supplementary Information accompanies the paper on Hypertension Research website (http://www.nature.com/hr) 